\title{
The Macy Study: A Framework for Consensus
}

\author{
Allan J. Formicola, D.D.S., M.S.; Howard Bailit, D.M.D., Ph.D.; Tryfon Beazoglou, Ph.D.; \\ Lisa A. Tedesco, Ph.D. \\ Dr. Formicola is Professor of Dentistry and former Dean, School of Dental and Oral Surgery and currently Vice Dean for the \\ Center for Community Health Partnerships, Columbia University Medical Center; Dr. Bailit is Professor Emeritus and Director, \\ Health Policy and Primary Care Research Center, University of Connecticut Health Center and Adjunct Professor, Columbia \\ University, School of Dental and Oral Surgery; Dr. Beazoglou is Professor, School of Dental Medicine, University of Connecticut \\ Health Center; Dr. Tedesco is Professor at the University of Michigan, School of Dentistry, and is a 2005-06 Visiting Professor at \\ Columbia University, School of Dental and Oral Surgery, and Visiting Fellow at the Center for Community Health Partnerships. \\ Direct correspondence and requests for reprints to Dr. Allan J. Formicola, Columbia University Medical Center, Center for \\ Community Health Partnerships, 630 West $168^{\text {th }}$ Street, Box 100, New York, NY 10032; 212-304-5214 phone; 212-544-1938 fax; \\ ajf3@columbia.edu.
}

Submitted for publication 7/26/05; accepted 8/17/05

$\mathrm{I}$ n September 2004, the Center for Community Health Partnerships at the Columbia University Medical Center received a three-year grant from the Josiah Macy Jr. Foundation to examine the growing financial problems of dental schools and to explore new educational models or strategies that will provide schools the resources needed to strengthen their educational, research, and service programs. In this commentary, we first discuss the current financial issues confronting dental schools from a broadbased perspective and consider the risks of continuing on the same financial path in the future. Then we will describe the process that the Macy study will employ to determine the financial and political feasibility of new educational models or strategies.

\section{Background}

Dental education made great strides in the twentieth century. Stimulated by the 1926 Gies Report, dental education has developed from a base of operations in predominantly proprietary dental schools prior to World War II to the present situation in which dental schools primarily function as components of academic health centers of many nationally respected research institutions. In this new setting most dental schools were able to gain sufficient resources to support a full-time faculty committed to scholarship in teaching, research, and patient care with strong basic science and clinical education programs.

Over the past decade the cost of education has risen steadily, while state and federal funding has not kept up with inflation or has actually declined.
At the same time, community practitioner incomes have risen at about twice the rate of faculty incomes, making it increasingly difficult to recruit and retain well-qualified clinical faculty. In response to these fiscal challenges, dental schools over the past ten to fifteen years have sharply increased student tuition and fees and deferred investments in facilities, learning resources, and other infrastructure areas.

The evidence suggests that most dental schools continue to operate at an acceptable level of quality, but these financial problems have made maintenance of program excellence an ongoing and ever increasing challenge. It should not be forgotten that seven dental schools, five in research universities, closed during the past two decades. While the specific reasons behind each closure may be unique, a combination of fiscal problems and an inability to sufficiently fit into the mission of the parent university are widely thought to have contributed to the closures. In addition to these closures, no major research university has started a dental school in the past twenty-five years despite the predicted shortage of dentists in the health care workforce. In fact, the primary driving force behind several of the recent and projected future openings of new dental schools is osteopathic medicine.

Seen from this perspective, the current financial problems of dental schools are of increasing concern. If they continue for the next ten to fifteen years, financing will likely threaten the place of dental education in research universities. This issue is of critical importance to both educators and practitioners. 
Dentistry's position as a learned, self-regulating profession of equal occupational prestige and responsibility to medicine and law depends upon having the stature and credibility in society that comes with being an integral part of research-intensive universities.

Unfortunately, adverse financial trends in general may well continue. State and federal governments are not likely to increase support substantially for health professional education, and reductions in Medicaid and Medicare program budgets will negatively impact the budgets of schools at all academic health centers. The recent budget of the National Institutes of Health has not even kept up with the growth of inflation, and the incomes of dental practitioners are projected to continue to grow faster than that of clinical faculty. The overall financial structure of dental schools will decline even if schools raise student tuition at the rate of the past ten years (about 5.4 percent annually). Tuition increases will not be sufficient to sustain the vitality of the educational, patient care, and research programs and at some point will exert a significantly negative impact on applications to dental school.

\section{Political Consensus}

To deal effectively with this problem, the leaders of the dental profession must come together and develop a consensus on needed changes in dental education and then actually implement the change. For two reasons, we are cautiously optimistic that this will happen. First, the major dental organizations have already recognized the financial challenges facing dental education and have called for educational reform. Examples include the several Educational Summits cosponsored by the American Dental Association (ADA) and the American Dental Education Association (ADEA); the efforts of the ADA Foundation to establish a large endowment to support dental education; and the recently formed ADEA Commission on Change and Innovation in Dental Education.

Second, we need to draw upon the lessons of other health professions that have made major change when it was recognized by all that the change strengthens the system of education. The pharmacy profession, for example, faced with equally serious challenges, made major reforms in its educational system. The leaders recognized that changes in drug dispensing technologies and the growing complexity of drug therapies for older and sicker patients required a significant change in the role of pharma- cists from mainly dispensing drugs to patient drug management. In the latter role, pharmacists participate in the drug therapy decision-making process with physicians and actively counsel and monitor patients in their use of drugs. To prepare graduates for this new role, the pharmacy education system added twelve months to its degree program and greatly strengthened basic medical science courses and patient care experiences. Now, all students complete a doctoral degree in pharmacy.

Clearly, now is the time for both the dental education and practice communities to come together and form a unifying vision of dental education in the twenty-first century. Only through consensus will it be possible to make the difficult choices that will address the growing financial problems and keep dental education a strong and integral part of research universities.

\section{The Macy Study}

The objectives of the Macy study are:

1. to develop new models of dental education that address the financial and educational challenges facing dental education and that impact on access to care across society;

2. to assess the economic and political feasibility of the more promising models; and

3. to convene a national conference of leaders and experts from stakeholder organizations to gain support for one or more of the models.

A National Advisory Committee of recognized leaders from dental education, practice, and public health and from academic medicine has been formed to achieve these objectives. The committee will provide guidance in all phases of the project.

A detailed study of the current financial structure of dental education is now under way with the goal of assessing the impact of reductions in budgets on selected operational and strategic outcomes over the past ten years. Projections on the financial structure of dental schools if the economic trends of the past ten years continue for the next ten are being investigated by Macy study staff.

Certainly, the biggest challenge for the study is identifying new models of dental education that, at face value, are educationally, politically, and financially feasible. The advice of the advisory committee to select the models that merit detailed investigation is critical in finding the answers to this challenge. Answers will depend upon in-depth financial analyses of the impact of the new models or strategies on revenues and expenses, the quality of den- 
tal education, and the political support for the model or strategy among leaders of the dental profession. Ideally, several models or strategies need to emerge, since no one model will meet the needs of all schools. Further, we understand that some schools have the resources to continue with their current educational approaches.

In the final year of the Macy study a national consensus conference will be held for all the major stakeholders concerned with dental education. These individuals will convene to review the results of this project. Hopefully, the conference will help these stakeholders reach a political consensus on the models most likely to soundly advance dental education in the twenty-first century and beyond.
The importance of finding a common vision or consensus for the future directions of dental education and then acting upon that vision cannot be overstated. Heifetz ${ }^{1}$ reminds us that "attention is the currency of leadership. Getting people to pay attention to tough issues rather than diversions is at the heart of strategy." The Macy study is designed to assist the profession in its complex task of understanding the current situation, projecting it forward, and seeking sound directions for the future.

\section{REFERENCES}

1. Heifetz RA. Leadership without easy answers. Cambridge: Harvard University Press, 1994. 